\title{
Structuring institutions to exploit learning technologies: a cybernetic model
}

\author{
Oleg Liber \\ Information Services, University of Wales, Bangor
}

The adoption of learning technologies has not fulfilled expectation in any sector of education. Arguably, it is the structure of educational institutions which is the main obstacle. Schools, colleges and universities were designed to allow the delivery of education by the few to the many at a time when the key technology was the printed page, and many of the organizational instruments that facilitated this are still with us today: timetables, classrooms, syllabuses and so on. These permit a particular style of education to take place, but result in a system where the complexity of learning needs is ignored New technologies can provide new organizational devices that recognize this complexity. These require careful design and imply a significant restructuring of institutional organization. This paper addresses how the tools provided by management cybernetics, in particular Stafford Beer's Viable System Model, allow the analysis of structural mechanisms and how they impact on organizational complexity. It describes how these tools can be used to redesign educational organizations, including identifying key points where technologies can be used to create structures that permit a more flexible exploitation of the opportunities offered by learning technologies. The current JTAP project Toolkit for the Management of Learning is offered as an example of a set of software tools that emerge from such a cybernetic analysis.

\section{Introduction}

Educational management is looking to Communication and Information Technologies (C\&IT) to make education cheaper and maybe even more effective (e.g. Dearing, 1997). But despite over two decades of computer-based learning, and despite the still considerable faith in the future possibilities of C\&IT, so far there is no evidence that this promise is anywhere near being realized. The reasons for this may be insufficient machines of adequate capability, a lack of training, inadequate networking and poor software. However, I believe that there is a more fundamental reason for its failure to make a significant impact: that the way education and its institutions are structured actively gets in the way of learning technology becoming effective. I suggest that the role of educational institutions is to connect learners with teachers, and that the teacher's purpose is to transform the world-views of the students. Rather than transmitters of knowledge, they are systems for managing learning conversations. Current forms of organization manage learning conversations in a particular way, which is inimical to the best use of learning technologies. C\&IT offers an alternative way of managing learning, but which cannot be layered on top of existing organizational structures. 


\section{Organizations as interlocking communication loops}

There are many ways of describing organizations (see Morgan, 1986). Beer's Viable System Model (VSM) describes them as being like a nervous system (Beer, 1981), and has elaborated a sophisticated cybernetic model. There is not the space to describe it fully here, but the key concept in this description is that the role of management is to manage complexity, following Ashby's Law of Requisite Variety (Ashby, 1956).

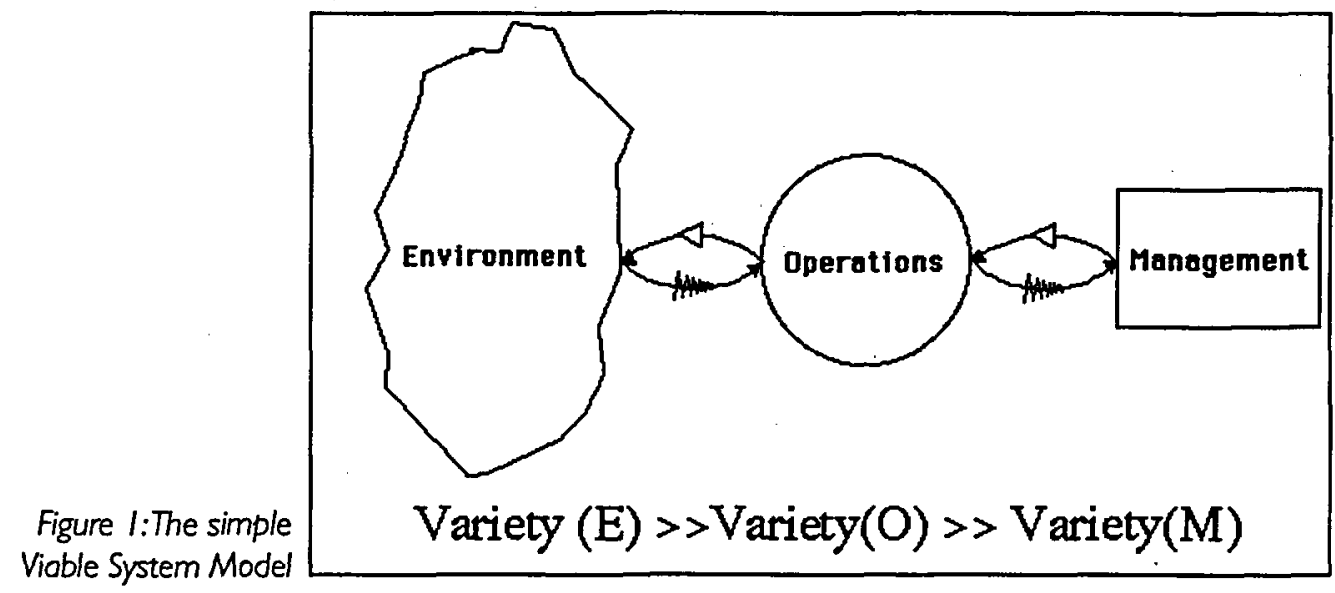

Figure 1 is a simple version of the VSM, showing how the key problem for management is the management of variety (the measure of complexity used in cybernetics). Because the organization's environment is far more complex than its operations, which in turn are far more complex than its management, these complexities need to managed. They either need to be attenuated, or the low variety side needs to be amplified by creating more options. How variety management is done determines the nature and range of its outputs. The full model provides a way of modelling organizations that identifies particular communication loops, and helps with diagnosis of problems and design of new structures. The VSM has been used widely in business and other organizations(see Espejo and Harnden, 1989); applying it to the organization of education provides valuable insights.

\section{Educational organizations}

For the purpose of this paper, I make a number of presuppositions which need to be made explicit. They are made from a constructivist viewpoint, embodying a particular view of learning.

First; it is necessary to establish what an educational institution is: what it does, and who the actors and other stakeholders are. This has been widely discussed elsewhere; nevertheless, here are my presuppositions:

(1) Educational institutions exist to enable specific transformations in students' worldviews, which we call learning.

(2) The people who effect this transformation are the students themselves. 
(3) Teachers create the context and conditions that permit them to do (2).

(4) Managers create the context and conditions that permit teachers to do (3).

This is a three-level model with students as the 'workers' and teachers as their 'managers', and then a further level of management. Another layer might be the sector management (e.g. HE funding councils). I do not agree with currently fashionable view of the student as customer (see Liber, 1997).

Because the world of knowledge is so complex, almost all institutions have to reduce its complexity to make it manageable. This is done by reducing knowledge to a number of categories or subjects (mathematics, psychology, history, etc.) which are embodied in schools or departments.

The second source of complexity is that of prospective students, which is also reduced through categorizing students into available subjects, with entry requirements geared to manage this low-complexity model. In schonls, students' complexity is also reduced by streaming. For example, a thousand students in a school are typically reduced by agegrouping to five age archetypes, and by 'ability' grouping into six or seven ability archetypes. One thousand students are reduced to thirty or so archetypes.

Subject departments then take their subject with all its complexity, and reduce it to a set of courses, each with a curriculum, a lecture programme, reading lists and so on, with performance measured by assignments and examinations. Students are restricted as to which courses can be done in which order, and timetables enable the whole to take place. Figure 2 shows how this is represented using the VSM.

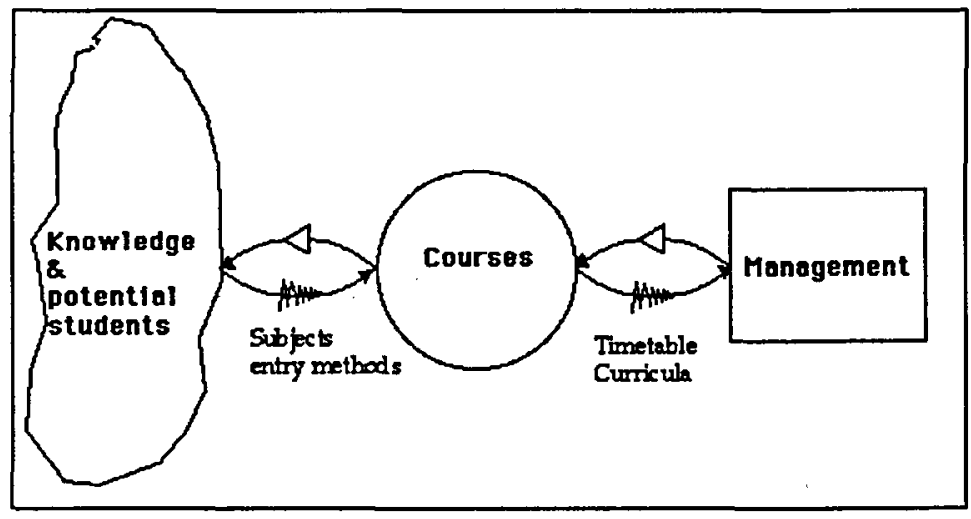

Figure 2: Institutional management of complexity

I am not criticizing establishments for doing this; rather, I wish simply to state that this is all to do with necessary management of complexity and not with learning per se. However, there is a price to be paid. Knowledge is broken up into a certain number of one hour (or so) chunks, whether or not this suits the subject matter. Students, no matter their unique skills, knowledge, aptitudes and interests, follow an identical curricular diet. Transdisciplinary work is difficult to sustain; despite the good intentions of modular systems, timetabling and other structures make it practically impossible.

The person who has to deal with the lost complexity is the teacher, who within the constraints described has to manage the complexity of the students in their charge. Within 
their classroom organization, the approach they use determines how complexity is managed. Once again, they have to manage the complexity of the knowledge domain for their course, and the complexity of the students in their charge. If they teach formally, then they reduce the complexity of the knowledge domain to their utterances, perhaps amplified by reading lists, and by limited discussion. Formal teaching also ignores the students' complexity, treating them all as if they were identical. Tutorials ameliorate this, but there is little (ever less) time for it. Figure 3 shows a simple model of the formal classroom.

Figure 3:The formal teaching approach

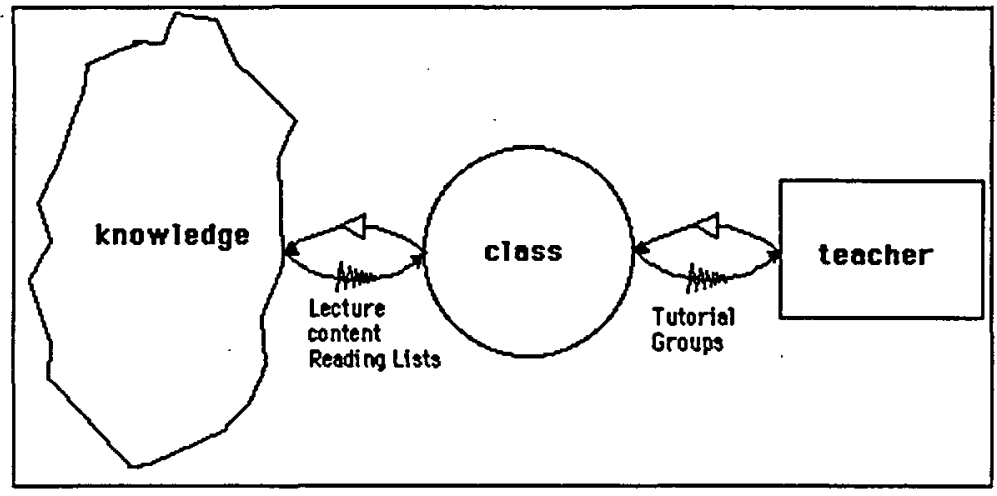

\section{Tools for managing complexity}

Because this has been the way of managing education for a long time, it has become accepted as the 'normal' organizational form. Subject distinctions have been around a long time, and seem to be the natural way of organizing knowledge; and to learn them we need syllabuses, do we not? And we could not let anyone study any part of any subject, at any time, at any level, to any depth, could we?

Things can be different. The Oxford tutorial model, for example, recognizes individuality; research degrees can permit trans-disciplinary work; but these approaches are expensive. Resource-based learning can also address individuality, but puts severe demands on teachers to collect, organize and manage learning resources. It also requires that teachers get to know their students rather well, and find out their needs, interests, aptitudes and learning styles. Resource-based learning schemes have been used in schools for many years' (see, for example, Liber, 1994), and have permitted classrooms to be de-streamed. In recent years, resource-based learning has gained its followers in higher education; in this case this is mainly due to the promise of Computer-Assisted Learning (CAL).

The problem, then, of the resource-based approach is the requirement for the teacher to manage two sources of complexity: the resource base and the student group. The Toolkit for the Management of Learning (TOOMOL) is a project funded by the Joint Information Systems Council Technology Application Programme (JTAP), and is developing tools that help with these problems. It provides a computer-based tool that allows teachers easily to build a database of resources, which they can structure according to the courses they teach. In a similar way, it allows them to build student profiles containing information about their backgrounds and previous learning. These then allow the teacher to establish the kinds of 
resources that may meet individual students' needs, and to deliver them directly to the students or over the Internet. Students also have a similar tool, which contains their developing profiles for each module or course, along with the resources that have been suggested to them by their teachers.

The resources may be texts in books in libraries, pages on the World Wide Web, CAL packages, lecture programmes, electronic discussion groups, or other students involved in similar work. The tool will launch appropriate software for any of these: connect to the Library, or launch a Web browser, a CAL package, or an email or conferencing client.

Although TOOMOL encourages teachers to adopt a resource-based approach by making its management much easier, the constraints of institutional organization remain. However, once a resource-based approach becomes dominant, constraints can begin to be lifted. When lectures become unusual and special events, instead of the main form of educational contact, timetabling becomes a less central problem. As students begin to develop learning profiles which can be made accessible to the teaching staff, guidance becomes tractable, and allows individual, trans-disciplinary courses to be designed, and can make the lifelong learning experience coherent. The need for strict subject-based organization is reduced, and allows teachers to operate in a more independent way, making alliances with others across the institution. Of course, mechanisms to ensure quality need to be put in place, but these do not have to be so departmentally based.

At the next level, if a resource-based approach is adopted more widely, there is no reason why students should not study at several universities, not only taking different modules at different places, but having tutors from different universities for a single course.

All of this can be made possible by using technology for what it is good at: helping to manage complexity. To achieve this level of inter-working using existing management approaches and mechanisms is impossible, and as long as these predominate, the true potential of technologies for learning will not be released. But if technology is used to substitute these management mechanisms, then the individuality of learners can be respected, and their creativity unleashed. The challenge for education is to make the transformation.

Unfortunately the signs are not good. At the next level of educational organization, national government, mechanisms seem to be being put in place that make this impossible. In schools, the National Curriculum defines what is 'proper' learning in each subject at every age, enshrining the destruction of complexity in law. Similar moves are being discussed for higher education. The Teaching Quality Assessment process (TQA) encourages convergence between departments in different universities, reducing diversity. The Research Assessment Exercise encourages 'safe' research at the centre of the subject domain, whereas the real challenge for research is at the edges of a discipline, where it rubs up against another. Central educational management needs to recognize that it must devise tools that ensure quality while promoting diversity, creativity, and risk-taking, and recognizing that sometimes this may go wrong.

\section{Conclusion}

I have used principles from Beer's VSM to argue that the way education has traditionally been (and is still) organized is concerned with the reduction of the complexity of knowledge and the learner group to make the problem of education tractable. New 
communication and information technologies provide new tools for organizing education that can permit much more flexibility both in individual learning and in the structure of permissible courses. Further, they can allow much greater co-operation between educational institutions, and facilitate the much vaunted learning society and lifelong learning. Unfortunately, existing modes of organization, in the classroom, in the institution and in the education system as a whole, are actively preventing these possibilities from taking place. Redesign of these structures is needed if the promise of new learning technologies is to be realized, along with the development of new technological tools for the management of learning.

\section{References}

Ashby, W.R. (1960), Design for a Brain, London: Chapman \& Hall.

Beer, S. (1981), Brain of the Firm, Chichester: John Wiley.

Dearing, R. et al (1997), Higher Education in the Learning Society, Report of the National Committee of Inquiry into Higher Education. London: NCIHE Publications (HMSO), July.

Espejo, R. and Harnden, R. (eds) (1989), The Viable System Model, Chichester: John Wiley.

Liber, O. (1994), 'Managing resource-based learning' in Foot, H. C. et al (eds), Group and Interactive Learning, Southampton: Computational Mechanics, 183-8.

Liber, O. (1997), Letter to The Times Higher, 1 August, 13.

Morgan, G. (1986), Images of Organization, Beverley Hills, CA: Sage. 